The Journal of Headache and Pain has successfully concluded its first year of activity, with the regular publication of three issues and two supplements. Attaining this goal is an excellent recognition of the validity of the journal and the certainty that we have overcome the most difficult obstacle to its growth and diffusion: the first year. The journal received many manuscripts from all corners of the world, which permitted us to publish papers of high scientific value, together with contributions coming from our younger colleagues and researchers from emerging countries.

The review of the manuscripts was strictly anonymous, and the authors received a large number of constructive comments which allowed them to greatly improve the quality of their papers. In some cases, an extensive exchange of correspondence was carried out with reciprocal satisfaction. As I wrote in the first issue, I believe that research should be free in all its phases and in particular in the educational and divulgation phases, which are primary objectives of the journal. The Journal of Headache and Pain would like to continue in these two main directions by striving for the greatest quality of the journal, and at the same time offering new possibilities of growth to less experienced scientists.
We are particularly pleased to inform our readers that the journal has received a great number of subscriptions during the first year, and that from the first issue of the year 2001 the journal will become the official journal of the Italian Society of Pain Clinicians. Therefore, we have reached another qualifying goal previously stated in the first issue: we are not just another journal dedicated to headache, but a journal devoted to the wider field of pain. Pain is one of the most important problems of public health, and it is not the strict prerogative of one single discipline. The multidisciplinary nature that characterizes The Journal of Headache and Pain, which covers many fields of medical science from basic science to neurology, algology, child and adolescent neuropsychiatry, emergency medicine, psychiatry, anesthesiology, internal medicine and clinical pharmacology, has been increased to reflect this new reality. However, the structure of the journal, which includes editorials, original papers, review articles, letters to the editor and news, has more or less remained unchanged.

I would like to draw the reader's attention to Rapid Communications, an innovative section, which allows the publication of results of high scientific importance, in short time. Eminent researchers have been enlisted to debate important and con- 
troversial subjects for the Pros and Cons section. It is our hope that this section, which is at the moment only in its initial phase, permits discussions on the state of the art, and on the highlights and shadows of the complex headache and pain field, and outlines the future roads of research to follow. In the view of promoting intense development and scientific debate, I would like to renew my invitation to all readers to submit an original article or review for one of the future issues. The Editorial Board thanks SpringerVerlag for editorial assistance and for the attractive graphic lay-out.

The Journal of Headache and Pain is accessible through the Springer LINK Information Service at http://link.springer.de/link/service/jour nals/10194/. The journal also thanks all the reviewers, whose contributions have allowed the continuous improvement in the quality of the scientific papers submitted and consequently the international profile of the journal, which from the year 2001, will be included in the Excerpta Medica EMBASE and Elsevier BIOBASE databases. Special thanks go to the journal's Co-Editor, the Associate Editors, the members of the Advisory Board and the Editorial staff, and to all the colleagues who have given their continuous support throughout the year. For The Journal of Headache and Pain, the third millennium has begun with the "kite" soaring high in the blue sky.

\section{Virgilio Gallai}

Editor-in-Chief 